\title{
FORMAÇÃO DA TAXA DE JUROS NO BRASIL -Considerações até o início do século XXI
}

Moisés da Silva Martins

UNOESTE/FATEC

\section{RESUMO}

Com esse trabalho pretendeu-se discutir e analisar a formação e a importância da taxa de juros no Brasil e como a mesma evoluiu com os diversos planos econômicos até atingir as mudanças nos anos iniciais do século XXI, bem como mostrar de que forma eram e são feitos em bancos comerciais, o calculo do spread. Se as taxas juros é um dos principais instrumentos de diagnóstico da saúde econômica de uma nação, pois permite saber se o país está atravessando um período de recessão ou de crescimento econômico, desta maneira, acreditou-se ser possível elaborar um acompanhamento deste instrumento que pode ser herói ou vilão de uma economia.

\section{INTRODUÇÃO}

\section{A EVOLUÇÃO DA SOCIEDADE : A CRIAÇÃO DA MOEDA E DOS JUROS}

A partir do momento em que o homem passou a viver e a se organizar em sociedade, começou a criar instrumentos que facilitassem sua vida. E um dos instrumentos mais importantes foi a moeda. O economista Campbell R. McConnel em seu livro Elementary Economics destaca:

\footnotetext{
"A moeda - uma das invenções verdadeiramente grandes do homem constitui o mais fascinante e um dos mais cruciais elementos da Ciência Econômica. A moeda enfeitiça, é um enigma que cativa. É muito mais do que um componente passivo da organização econômica.

Quando aplicada adequadamente, é a moeda que impulsiona os fluxos da produção e da renda, existentes em todas as economias.

Um sistema monetário bem conduzido pode levar ao pleno emprego. Mas, quando mal dirigido, pode conduzir a graves flutuações e mesmo à total destruição da ordem econômica."
}

Observou-se, então, que as sociedades, após atingir um estágio de organização, necessitavam da formação de um sistema que facilitasse as transações econômicas. E o sistema de trocas levou ao surgimento e ao aperfeiçoamento de uma correspondente organização monetária.

Assim a moeda evoluiu desde o sistema mais primitivo de troca, conhecido como escambo, passando pelas mercadorias-moeda pelo metalismo que passou a ter sua emissão oficial e de curso legal de pagamento por algumas nações da Antiguidade, pela moeda-papel que 
deu origem ao sistema bancário atual devido ao emprego generalizado de metais preciosos e correspondente emissão de certificados e letras de câmbio, até chegar à descoberta da operacionalidade do papel-moeda, que hoje é conhecido como dinheiro, possuindo o Governo, através do Banco Central, o monopólio de sua emissão e controle.

Não existe uma definição aceita universalmente do que é moeda Gastaldi ( 1995: 221 ), sobre o conceito da moeda, argumenta que:

"A moeda, em última análise, é a representação em dinheiro do preço, o qual, por sua vez, é taxa do valor dos bens a serem permutados.(...) Antes das economias monetárias, nos primórdios das civilizações, o preço era representado, tão somente, pela maior ou menor utilidade que as coisas trocadas proporcionavam às partes permutantes."

Mas pode-se compreendê-la a partir de suas funções:

a) Meio de troca: a moeda constitui um instrumento capaz de presidir as transações de consumo;

b) Unidade de valor: ela permite que os bens e serviços a serem transacionados tenham um valor monetário, ou seja, um preço;

c) Reserva de valor: a moeda pode ser guardada para uso posterior assim ela constituindo na observação keynesiana uma ponte entre passado, presente e futuro. Diante disso, Montoro e Troster ( 1998 : 343 ) destacam que "A moeda, para cumprir bem essa função, deve possuir valor estável, de forma que quem a possuir tenha idéia precisa de quanto pode obter em troca".

A moeda é um instrumento imprescindível para o funcionamento e a organização dos modernos sistemas econômicos. A natureza da moeda, na fase atual da economia monetária, corresponde a uma característica essencialmente institucional, de cunho econômico e social; o que justifica as nações terem tanto zelo por elas.

Cada país adota sua unidade monetária, que no Brasil foram as seguintes: 


\begin{tabular}{|c|c|c|c|}
\hline DENOMINAÇÃO & síMBOLO & VIGÊNCIA & PARIDADE \\
\hline $\begin{array}{l}\text { REAL: Período Colonial até } 07 / 10 / 1833 \text {. O plural de REAL era } \\
\text { RÉIS. } \\
\text { MIL RÉIS: Vigorou a partir do Segundo Império. Um conto de réis } \\
=1.000 .000 \text { réis. }\end{array}$ & $\begin{array}{l}\text { R } \\
\text { Rs }\end{array}$ & $\begin{array}{l}\text { Até } \\
07 / 10 / 1833 \\
08 / 10 / 1833 \text { a } \\
31 / 10 / 1942\end{array}$ & $\begin{array}{l}R 1 \$ 2000=1 / 8 \text { de } \\
\text { ouro de } 22 K \\
R 2 \$ 5000=1 / 8 \text { de } \\
\text { ouro de } 22 K\end{array}$ \\
\hline $\begin{array}{l}\text { CRUZEIRO: Em 1942, com a inflação durante a 2a Guerra, o Real } \\
\text { vira Cruzeiro e } 3 \text { zeros são cortados. }\end{array}$ & $\mathrm{Cr} \$$ & $\begin{array}{l}01 / 11 / 42 \text { a } \\
12 / 02 / 67\end{array}$ & $\begin{array}{l}1.000 \text { réis = } \\
1 \text { cruzeiro }\end{array}$ \\
\hline $\begin{array}{l}\text { CRUZEIRO NOVO: Em 13/11/1965, com a inflação, o poder de } \\
\text { compra do Cruzeiro é corroído, mais } 3 \text { zeros são cortados. }\end{array}$ & $\mathrm{NCr} \$$ & $\begin{array}{l}13 / 02 / 67 \text { a } \\
14 / 05 / 70\end{array}$ & $\begin{array}{l}1.000 \text { cruzeiros }= \\
1 \text { cruzeiro novo }\end{array}$ \\
\hline $\begin{array}{l}\text { CRUZEIRO: Em 31/01/1970 o Cruzeiro Novo volta a ser chamado } \\
\text { de Cruzeiro. }\end{array}$ & $\mathrm{Cr} \$$ & $\begin{array}{l}15 / 05 / 70 \text { a } \\
27 / 02 / 86\end{array}$ & $\begin{array}{l}1 \text { cruzeiro novo = } \\
1 \text { cruzeiro }\end{array}$ \\
\hline $\begin{array}{l}\text { CRUZADO: Em 28/02/86 o Plano Cruzado corta } 3 \text { zeros da } \\
\text { moeda, que passa a se chamar Cruzado. }\end{array}$ & $\mathrm{Cz} \$$ & $\begin{array}{l}28 / 02 / 86 \text { a } \\
15 / 01 / 89\end{array}$ & $\begin{array}{l}1.000 \text { cruzeiros }= \\
1 \text { cruzado }\end{array}$ \\
\hline $\begin{array}{l}\text { CRUZADO NOVO: Em 31/01/1989, o Plano Verão congelou os } \\
\text { preços, cria o Cruzado Novo e corta } 3 \text { zeros. }\end{array}$ & $\mathrm{NCz} \$$ & $\begin{array}{l}16 / 01 / 89 \text { a } \\
15 / 03 / 90\end{array}$ & $\begin{array}{l}1.000 \text { cruzados }= \\
1 \text { cruzado novo }\end{array}$ \\
\hline $\begin{array}{l}\text { CRUZEIRO: Em março/90, O Presidente Collor bloqueia as aplic. } \\
\text { Financeiras e a moeda volta a ser o Cruzeiro. }\end{array}$ & $\mathrm{Cr} \$$ & $\begin{array}{l}16 / 03 / 90 \text { a } \\
31 / 07 / 93\end{array}$ & $\begin{array}{l}1 \text { cruzado novo = } \\
1 \text { cruzeiro }\end{array}$ \\
\hline $\begin{array}{l}\text { CRUZEIRO REAL: Em agosto/93, a moeda fica sem } 3 \text { zeros } \\
\text { novamente e vira Cruzeiro Real. Nos } 11 \text { meses de sua existência, } \\
\text { o cruzeiro real acumulou uma inflação de } 3700 \%\end{array}$ & CR\$ & $\begin{array}{l}01 / 08 / 93 \text { a } \\
30 / 06 / 94\end{array}$ & $\begin{array}{l}1.000 \text { cruzeiros }= \\
1 \text { cruzeiro real }\end{array}$ \\
\hline $\begin{array}{l}\text { REAL: Em 01/07/94, o Presidente Itamar Franco cria o Real, cujo } \\
\text { plural é Reais. Antes que entrasse em circulação, passou a } \\
\text { vigorar uma unidade de conta, não de troca, chamada URV - } \\
\text { Unidade Real de Valor, com variação diária. A economia era } \\
\text { estimulada a usá-la como referência. Quando a URV chegou a } \\
2750 \text { cruzeiros reais, a nova moeda, real, entrou em vigor. }\end{array}$ & $\mathrm{R} \$$ & 01/07/94 a . & $\begin{array}{l}2.750 \text { cruz. } \text { reais }= \\
1 \text { real }\end{array}$ \\
\hline
\end{tabular}

Dentre as funções da moeda, há de se destacar a função de reserva de valor, pois os indivíduos, diante de sua posse, podem guardá-la por motivos diferentes. A disponibilidade imediata da moeda leva ao conceito de liquidez. De maneira geral, os agentes econômicos têm preferência pela liquidez da moeda. Contudo, as pessoas e as empresas para manter em saldo monetário fazem uma escolha intertemporal diante de três situações. Na primeira, eles retêm moeda para transações de forma a realizar as operações de consumo de alimentos, transporte, aluguel etc, para satisfazerem suas necessidades diárias. Na segunda razão, as pessoas e as empresas precisam reter moeda por precaução, de modo a atender algum imprevisto ou incerteza do futuro, então elas poupam moeda. Na última escolha, os agentes econômicos retêm moeda para especulação, de modo que procuram obter uma vantagem financeira diante do risco das oportunidades descobertas. 
A escolha intertemporal das duas primeiras razões está relacionada ao nível de renda dos agentes. Assim Montoro e Troster ( 1998 : 356 ) concluem: "É de se esperar que quanto maior a renda, maior a necessidade para transações e por precaução." mas os agentes econômicos ao optarem pela especulação, estão interessados em receber um rendimento por possuir essa moeda (é um custo para quem precisa pedir emprestado). Esse rendimento (ou custo) que corresponde a uma compensação pela aplicação (ou uso) do capital chama-se juro. E a demanda de moeda para especulação está relacionada inversamente ao rendimento da taxa de juros. Referindo-se à taxa de juros Gastaldi assinala:

“A remuneração do capital aplicado poderá ser maior ou menor, variando conforme a quantidade de capital emprestado, o prazo ou duração do empréstimo, e seu quantum, a abundância ou a escassez de capitais disponíveis, fluindo para o estabelecimento dessa taxa, ainda o risco pelo empréstimo e o eventual desgaste dos bens nos quais ele se transforma."

Na Antiguidade, diferentes legislações proibiam o empréstimo a juro, como a Lei Mosaica para os judeus e a Lei Genucia ( 322 a.C. ) para os romanos. Para os cristãos, o juro era considerado como usura, pois o dinheiro deveria ser usado apenas para facilitar as trocas; apenas solicitava empréstimo quem se encontrava em situação angustiante de muita necessidade e era considerado cruel o credor que explorava pessoas nessa situação. Na segunda metade da Idade Média, a doutrina canônica foi renovada pela doutrina de São Tomás de Aquino. A doutrina canônica foi defendida pelos tratadistas, na França, que combatiam os juros (Bodim, no século XVI, Pothier, no século XVII e Mirabeau, no século XVIII ). A reforma calvinista (século XVI) trouxe novos conceitos ao juro e aos negócios de dinheiro, determinando, desta forma, novos rumos aos sistemas de crédito e bancário.

No século XVIII, na França, o economista Anne Turgot estabelece a teoria da frutificação inspirada nos conceitos calvinistas. Neste mesmo século Adam Smith procura justificar o juro como sendo o preço da abstinência à produtividade do capital emprestado, é a teoria da abstinência. Mais tarde Jean B. Say (1803), formula a teoria da utilização baseado na concepção de que a utilização dos fatores de produção: terra, homem (trabalho) e capital devem ser remunerados, sendo o juro o pagamento de sua utilização. A oposição a essas teorias veio com os socialistas, principalmente na figura de Karl Marx, que formularam a teoria da espoliação, em que consideravam o juro como a diferença entre o efetivamente pago ao trabalhador e 0 rendimento obtido pela aplicação desse trabalho na produção. Finalmente, a moderna economia está baseada principalmente na teoria de John M. Kaynes que Pinho ( $1998: 49$ ) considera: 
"Keynes criticou a Lei de Say e inverteu a perspectiva de exame da moeda em movimento ( enquanto 'gasta' ) para analisá-la quando entesourada ou guardada; reinterpretou a taxa de juro; analisou a poupança e o consumo; estudou sob novo enfoque a determinação do investimento e o equilíbrio agregativo; [...]"

\section{JUROS COMO INSTRUMENTO DE POLÍTICA MONETÁRIA}

O maior desafio dos países é realizar simultaneamente sua política macroeconômica voltada aos seguintes aspectos: estabilidade de preços (níveis de inflação baixos ou nulos), crescimento econômico (sem recessão), comércio exterior equilibrado (taxa de câmbio estável), alto nível de emprego e maior distribuição de renda. Um dos meios de política macroeconômica é a política monetária e esta é que irá regular a moeda e a taxa de juros. Duas proposições teóricas se conflitaram para explicar as alterações na taxa de juros: a clássica e a keynesiana. Na versão clássica (sintetizada pela lei de mercados de Say: “a oferta cria sua própria procura ocasionando o pleno emprego" ), a moeda, é apenas um instrumento de troca, e a função dos juros é manter um equilíbrio diante das decisões de poupar e investir. Na versão keynesiana, a política monetária afeta a taxa de juros, através da intersecção das funções de oferta e procura de moeda.

Baseando-se na teoria keynesiana, o país, ao montar sua estratégia de política monetária deve analisar o Mercado Monetário e assim determinar a demanda de moeda (necessidade de transações dos agentes econômicos, ou seja, liquidez) e oferta de moeda (definida pelo Banco Central) considerando também o risco inerente da economia, de maneira que, encontrar a taxa de juros de equilíbrio, se torna uma tarefa extremamente complicada para os economistas. 0 Banco Central é a autoridade monetária que possui as prerrogativas de regulamentação e manejo dos instrumentos de política monetária como: emissão de moeda, reservas compulsórias, open-market e política de crédito que afetam diretamente a oferta monetária, consequentemente a taxa de juros. Alterando-se os juros, a procura de moeda se alterará, especialmente os investimentos das empresas. Quando a economia está se expandindo, as empresas necessitam de capital para investimentos. Essa procura por capital eleva a taxa de juros, por outro lado, as pressões inflacionárias são mais fortes durante os boons econômicos e isso exerce uma pressão de alta sobre o juros no momento em que o Banco Central diminui a oferta monetária para conter a inflação. As condições se invertem durante recessões quando as atividades retraídas reduzem a demanda de crédito, a inflação cai e o resultado é uma queda na taxa de juros. 
Antes do plano Real o que se verificou foi a taxa básica Selic diretamente relacionada ao índice inflacionário, - "inflação elevada - taxa básica de juros alta, chamado de efeito Fisher" justamente uma política monetária voltada para diminuição da oferta monetária para conter a expansão do consumo. Um pouco antes,em 1989, durante o governo do Presidente José Sarney, mesmo após o Plano Econômico de Verão, a inflação atingiu um pico de 1.782,89\% para uma taxa básica da Selic de $2.407,28 \%$. No ano de 1.993 , ocorreu um segundo pico inflacionário, quando esta atingiu seu índice mais alto 2.708,60\%, e a taxa básica da Selic já atingia a marca de $3.060,01 \%$. No período seguinte, após o Plano Real, mesmo com a inflação relativamente estabilizada, as autoridades monetárias tiveram que elevar a taxa básica de juros Selic, devido as crises econômicas ocorridas fora do Brasil. Assim, surgiram os picos de alta de juros durante a Crise no México em 1.995, Crise Asiática em 1.998 e Crise Russa no final de 1998. No início de 1.999, houve um novo pico de juros, mas em decorrência da desvalorização do real.

\section{JUROS BRASILEIRO E DO MUNDO}

As taxas de juros brasileiras sempre estiveram entre as mais elevadas do mundo. Isso devese em parte às condições macroeconômicas da época, mas que reverteu no início do governo Fernando Henrique Cardoso. Essa reversão deveu-se à política monetária austera adotada a partir da implantação do Plano Real, voltada ao controle da inflação. Porém, deve-se acrescentar ao formar a taxa de juros brasileira o risco Brasil. O risco do país que é uma sobretaxa que cada nação paga sobre o custo do dinheiro para o Tesouro dos EUA - isso porque os títulos americanos eram considerados de risco zero. 


\section{Figura 1}

Mercado A: Títulos de baixo risco

Mercado B: Títulos de alto risco
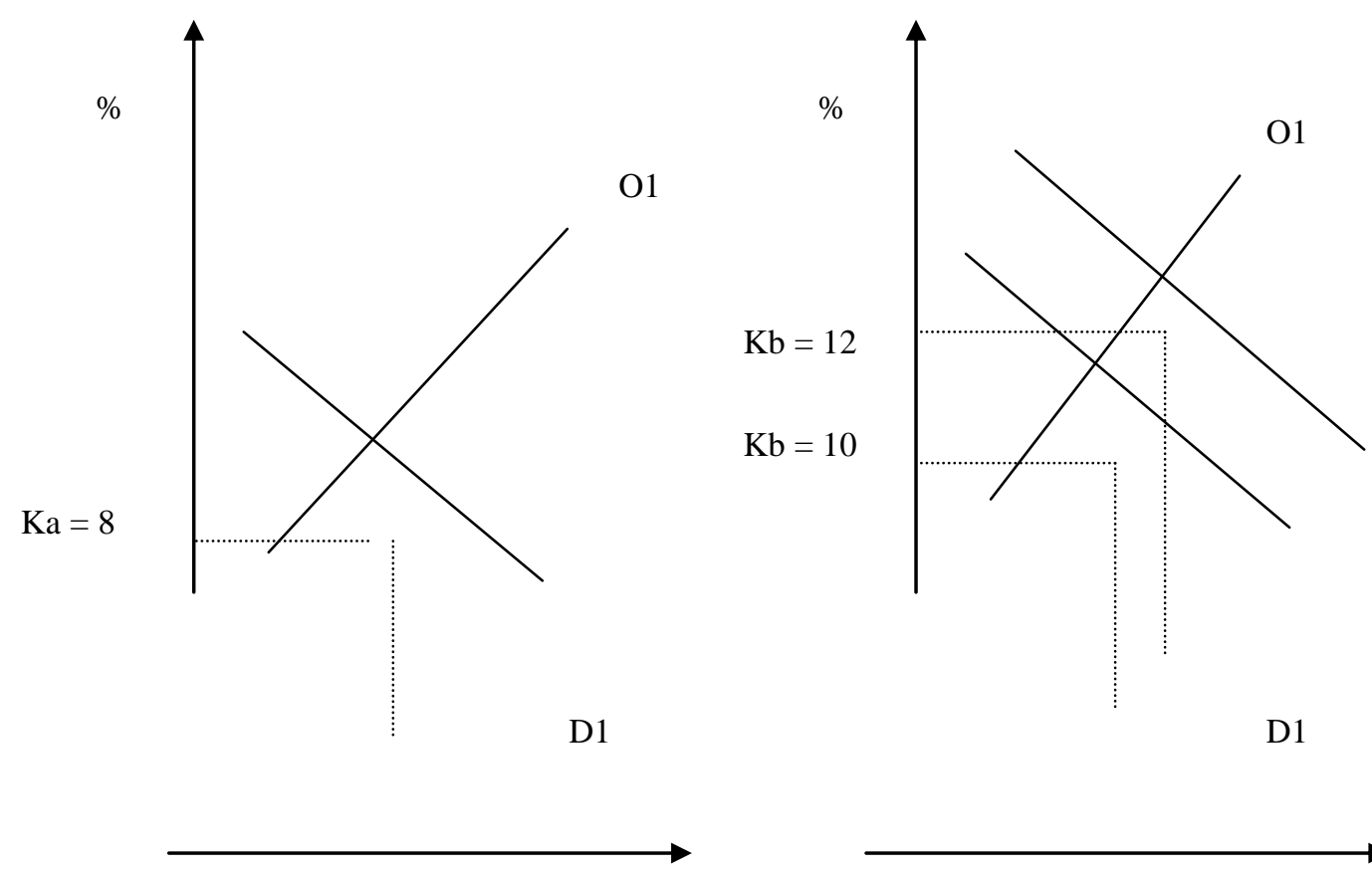

D2

D1

A explicação está na Figura 1, que mostra graficamente o potencial de oferta e demanda de moeda em dois países, denominados de Mercados A e Mercado B. Os investidores que desejam aplicar seus recursos sem muito risco podem obter um retorno de $8 \%$ no Mercado A, pois os tomadores de empréstimo possuem um crédito forte, qualificam-se nesse mercado para obterem recursos a um custo de $8 \%$. Os tomadores mais arriscados e os investidores mais dispostos em assumir riscos para ganhar mais, procuram o Mercado $B$, onde a taxa é de 10 \%. Se a demanda por capital aumentar no Mercado B, como ocorre em países com problemas econômicos - inflação, necessidade de cobrir déficit, necessidade de investimento que aumentam o risco, a curva de demanda passará para D2, onde a taxa de juros aumentará para $12 \%$. Assim o investidor só investe se houver uma garantia mínima de retorno.

Existem empresas especializadas em classificar o risco de uma nação e quanto maior o risco maior o juros a ser pago. Como exemplo podemos citar a Standard \& Poor's, que em 1.999 classificou o Brasil em B+ ( risco alto ) - a escala possui 19 níveis, de CCC+ ( maior risco ) a AAA ( menor risco ) - e em 03/01/2001 alterou para BBB- ( risco médio). 
Ao comparar a taxa real de juros (taxa básica de juros descontada a inflação) do Brasil com outros países, verifica-se que a brasileira, no fim do século XX, estava em segundo lugar perdendo apenas para a Indonésia.

Para Nilson Vargas ( reportagem de 05/04/2000, revista Veja ) :

"Juros altos tendem a ser vistos como um gol contra que o governo marca. Eles retraem o consumo e inflam as dividas de pessoas, das empresas e do próprio governo. Também inviabilizam investimentos que podem gerar empregos e travam o avanço econômico do país."

\section{JUROS E SPREAD BANCÁRIO NO BRASIL}

O spread é a diferença entre a taxa básica de juros e as taxas finais cobradas do tomador nos empréstimos.

A taxa básica de juros, na virada do século mostrava sinais de baixa devido às boas perspectivas econômicas apresentadas pelo Brasil que já vinha mudando positivamente os cenários de avaliação de risco pelos economistas brasileiros e estrangeiros e no início de 2001 a baixa da taxa básica de juros dos EUA - 6,5\% para 6\% - gerou muito otimismo. Mas, o spread bancário brasileiro se encontrava em patamares bastante elevados o que encarecia demais as taxas finais dos empréstimos. Este assunto foi objeto de estudo realizado pelo Departamento de Estudos e Pesquisas (DEPEP) do Banco Central, que teve como objetivo identificar e explicar o comportamento do spread bancário no Brasil.

Tomando-se a média do trimestre maio/julho de 1999 os analistas do Banco Central chegaram às seguintes conclusões em relação ao custo dos empréstimos e composição do spread :

\section{Tabela 1}

\begin{tabular}{|c|c|c|c|c|c|c|}
\hline Discriminação & \multicolumn{2}{|c|}{ Média Geral } & $\begin{array}{l}\text { Média } \\
\text { Física }\end{array}$ & Pessoa & \begin{tabular}{|l} 
Média \\
Jurídica
\end{tabular} & Pessoa \\
\hline Custo ao tomador (\% a.m.) & $5,17 \%$ & $100 \%$ & $6,75 \%$ & $100 \%$ & $4,31 \%$ & $100 \%$ \\
\hline Taxa de Captação (\% a.m.) & $1,60 \%$ & $31 \%$ & $1,60 \%$ & $24 \%$ & $1,60 \%$ & $37 \%$ \\
\hline Spread (\%a.m.) & $3,58 \%$ & $69 \%$ & $5,15 \%$ & $76 \%$ & $2,72 \%$ & $63 \%$ \\
\hline
\end{tabular}

Fonte: DEPEP-SP - Boletim “Juros e Spread Bancário no Brasil - out/1999”

Ao decompor os dados para analisar o motivo do spread atingir um índice de $69 \%$ na média geral, os analistas concluíram que a inadimplência é o custo que mais onerava o spread 
brasileiro ( $35 \%$ no período mai/jul/99 ), seguido do mark-up - despesas administrativas (22\%), lucro líquido (18\%) e impostos diretos (11\%) - e, finalmente, impostos indiretos que representavam $14 \%$.

Segundo os analistas da época do DEPEP-SP:

"O risco de crédito foi um fator determinante do elevado custo das operações de empréstimo, o que também explica a dificuldade ou mesmo a não concessão de empréstimos pelos bancos. Quando fazem operações de crédito, os bancos querem ter certeza de receber de volta os valores emprestados, mais juros pactuado, pois os intermediários financeiros têm obrigações com os seus depositantes. Como esta certeza não existe, mesmo para clientes de primeira linha, os bancos sempre cobram um adicional a título de risco de crédito, ou seja, uma valor associado à probabilidade de não receber o valor emprestado."

É o velho pensamento de que os "bons pagadores acabam pagando pelos maus", que já foi contestado por alguns banqueiros como Muhammad Yunus (1997 : 154): "Os bancos tradicionais constroem sua instituição de crédito baseados na desconfiança. Mas para nós (Banco Grameen) 'crédito' significa 'confiança'. Recuamos até os fundamentos da relação credor-financiado e construímos uma instituição baseada na confiança mútua, sem a intervenção de nenhum instrumento jurídico."

É importante destacar que em função do risco de crédito, o spread nas operações de crédito com pessoas físicas é superior ao das operações com pessoa jurídica.

\section{JUROS E A LEGISLAÇÃO BRASILEIRA}

A Constituição Federal em seu art. 192, § 3ㅇdestaca o seguinte em relação aos juros:

$\S$ 3ㅇ - As taxas de juros reais, nelas incluídas comissões e quaisquer outras remunerações direta ou indiretamente referidas à concessão de crédito, não poderão ser superiores a doze por cento ao ano; a cobrança acima deste limite será conceituada como crime de usura, punido, em todas as suas modalidades, nos termos que a lei determinar.

Não foi intenção deste trabalho elaborar um posicionamento teórico a respeito do ordenamento jurídico em relação ao juros, mas a Constituição de 1988 limitou a cobrança de juros ao patamar máximo de $12 \%$ a.a.. Como a Constituição é a lei máxima do país, este valor tem gerado inúmeros questionamentos na esfera jurídica, a respeito da cobrança ou não de juros acima do estipulado na Carta Magna. 
O entendimento jurisprudencial dominante esta no sentido de que essa regra não é autoaplicável (conforme entendimento do STF), dependendo sua eficácia de lei regulamentadora, pelo que se admite, até que isso aconteça, a cobrança de juros pelas instituições financeiras ou bancárias, em limite superior ao ali estabelecido. A decisão do STF ( 6 votos a 4 ) assim concluiu:

"Tendo a Constituição Federal, no único artigo em que trata do Sistema Financeiro Nacional (art.192), estabelecido que este será regulado por lei complementar, com observância do que determinou no caput, nos seus incisos e parágrafos, não é de se admitir a eficácia imediata e isolada do disposto em seu parágrafo 30 , sobre a taxa de juros reais ( $12 \%$ ao ano), até porque estes não foram conceituados. Só o tratamento global do Sistema Financeiro Nacional, na futura lei complementar, com observância de todas as normas do caput, dos incisos e parágrafos do art. 192, é que permitirá a incidência da referida norma sobre juros reais e desde que estes também sejam conceituados em tal diploma.

Em consequência, não são inconstitucionais os atos normativos em questão (parecer da Consultoria-Geral da República, aprovado pela Presidência da República e circular do Banco Central), o primeiro considerando não auto-aplicável a norma do parágrafo 3 ㅇ sobre juros reais de $12 \%$ ao ano, e a segunda determinando a observância da legislação anterior à Constituição de 1988, até o advento da lei complementar reguladora do Sistema Financeiro Nacional."

\section{(STF; ADIn 4-7-600-DF, RTJ 147/719-858)}

Outra questão de intenso debate jurídico é a respeito da capitalização dos juros o chamado "anatocismo". Conforme disposto na Lei de Usura (Decreto no 22.626/33), discorre a respeito do anatocismo nos seguintes termos:

"Art. 4ㅇ. É proibido contar juros dos juros; esta proibição não compreende a acumulação de juros vencidos aos saldos líquidos e conta-corrente de ano a ano."

O governo federal editou a Medida Provisória 1963-17 de 31/03/2000 que estabeleceu o seguinte:

"Art. 5‥ Nas operações realizadas pelas instituições integrantes do Sistema Financeiro Nacional, é admissível a capitalização de juros com periodicidade inferior a um ano.

Parágrafo único. Sempre que necessário ou quando solicitado pelo devedor, a apuração do valor exato da obrigação, ou de seu saldo devedor, será feita pelo credor por meio de planilha de cálculo que evidencie de modo claro, preciso e de fácil entendimento e compreensão, o valor principal da dívida, seus encargos e despesas contratuais, a parcela de 
juros e os critérios de sua incidência, a parcela correspondente a multas e demais penalidades contratuais."

É fato que também a questão do anatocismo tem sido intensamente discutida no meio jurídico. Mas é importante trazer à baila que de nada adianta discutir a maneira de cobrança dos juros - se serão juros simples ou juros compostos - se eles podem ser pactuados livremente pelas instituições financeiras, conforme normas do Conselho Monetário Nacional e jurisprudência do STF.

A matéria é polêmica e requer, portanto uma legislação específica a respeito do assunto e ao que parece os legisladores brasileiros não têm demostrado interesse em resolver rapidamente tal problema.

\section{CONCLUSÃO}

No decorrer do estudo, usando da metodologia exploratória, foram apresentados conceitos e aspectos sobre a formação e evolução das taxas de juros e, como as mesmas influenciadas pela globalização da economia, tornavam vulnerável o mercado financeiro do país. Notou-se que a legislação que regulamentava as taxas de juro no Brasil não era clara e que a demanda de moedas e numerários para auxiliar o desenvolvimento da nação não tinha o respaldo dos governantes da época.

\section{REFERÊNCIAS}

ROSSETTI, José Paschoal. Introdução à Economia, São Paulo: Editora Atlas, 1997.

ROSSETTI, José Paschoal. Introdução à Economia, São Paulo: Editora Atlas, 1977.

EQUIPE DE PROFESSORAS DA USP Manual de Economia, São Paulo: Editora Saraiva, 1998.

GASTALDI, J. Petrelli.Elementos de Economia Política, São Paulo: Editora Saraiva, 1998.

MANKIW, N. GREGORY. Macroeconomia, Rio de Janeiro: Editora LTC, 1997.

YUNUS, MUHAMMAD. O Banqueiro dos Pobres, São Paulo: Editora Ática, 1997.

VEJA, São Paulo: Editora Abril, Ano 33, no 14, 05/04/2000.

DEPEP-SP Juros e Spread Bancário no Brasil, Boletim Banco Central do Brasil, outubro de 1999.

DEPEP-SP Juros e Spread Bancário no Brasil, Boletim Banco Central do Brasil, novembro de 1999. 